\title{
Comparative Analysis of Higher Education Internationalization of China and USA from the Perspective of Policy Impacts -- A Mini Review
}

\author{
Fanzheng Gan ${ }^{1, a, ~}{ }^{\star}$, Peng Xiao ${ }^{2, b}$ \\ 1. School of International Finance \& Trade, Leeds Beckett University, Leeds, LS16 5LF, United \\ Kingdom \\ 2. Asia Education Institution, Singapore, 649812, Singapore \\ a, * ganfanzheng@gmail.com, b eric2015aei@gmail.com
}

\begin{abstract}
With the globalization development, the competition of higher education internationalization is intensifying in major countries with numbers of policies and changes emerge one after another. In order to explore the role of policies in the development of internationalization of higher education, this paper combines systematic policy-related documents review and case study to make a comparative analysis of the development process as well as the policies of internationalization of higher education in between China and the United States. It sorts out that the general development strategies which including policies for attracting overseas students, study abroad on public assignment, exchange projects of teachers and scientific researchers and the development of joint higher education programs. It also points out that the internationalization of higher education has become an important means of public and cultural diplomacy of large countries and an important way for countries to explode cultural exchanges, enhance the comprehensive strength of the country and continuously improve on its' national level strategies.
\end{abstract}

Keywords: Higher Education Internationalization; Education Policy; Policy Impacts; Life-cycle Theory.

\section{Introduction}

Higher education internationalization has been increasingly critical to the success of the educational system of a country and become one of the most important driving forces for the development of higher education (Wihlborg \& Robson, 2018). As was stated in the conference on world higher education in Paris in 1998, internationalization was proposed to be one of the challenges as well opportunities confronting the higher education in the 21 st century, as "because of the universality of knowledge, knowledge can only be deepened, developed, and spread with the joint efforts of international academic organizations. The internationalization of higher education is the goal of all academic institutions in the world" (UNESCO 1998). In addition, given the increasing economic globalization and the rapid economic development of the emerging economy countries, such as China and India, there has been an increasing trend of the: free flow of "international brains" from one country to the other. Accordingly, the higher education industries in typical immigrate countries, such as the USA, have benefited from their immigration policies and attracted a large number of international students (Wihlborg \& Robson, 2018). Although the increase in the number of international students cannot be regarded as the single factor of higher education internationalization, it has clearly driven the higher education systems in those countries toward a global perspective.

Amongst all the factors contributing to the internationalization of higher education, higher education policies have been regarded as one of the most important factors driving the internationalization development strategies (Hong, 2020). Though the development strategies of the higher education in different countries varies, while some focus on "going-out" to build collaboration with other countries some others tend to "getting-in" international institutions, scholars, and students (Palmer \& Cho, 2012). It is intuitive that universities would see it as a way of building an international profile or brand in order to gain the competitive advantages both domestically and globally (Lee, Liu 
$\& \mathrm{Wu}, 2020)$. Higher education internationalization means different international activities such as study abroad, international development projects, institutional agreements, or branch campuses (Huang, 2006). For some relevant interest groups, them can bring high profits. Meanwhile, with the achieving of high-quality education standards (e.g., curricula) by integrating the international dimension into teaching, research, and service functions of higher education (Huang, 2006). With the effectiveness of these policies, the competitiveness of higher education internationalization in the whole region or country will increase.

Besides the internationalization of higher education in the west world, such as the Englishspeaking countries, many fast-growing economies, such as China, have started to develop and internationalize their higher education to meet the needs of globalization and prepare to compete with universities in other countries. With its growing importance in global economic as well as cultural influence, many policies at the national level were developed and introduced. Since the economic reform and opening-up policy in the late 1980s, China has started to be open to the outside world in various ways. Hence, this process has also fuelled the Chinese higher education institutions to open to international higher education organization and universities (Hammond, 2016).

The past few decades have witnessed the fast rise of East Asia. The success of strong governmentled economic development in East Asia, starting from Japan followed by South Korea, Singapore and now China, has been related to the concepts of the "Developmental State" (Thompson, 1996) and "Confucian capitalism" (Vogel, 2013), and further related to the higher education development. It is believed that rather than become more western, the East Asian countries, such as China, will be placing a larger impact with respect to economic, political, and cultural aspects. Hence, the analysis of patterns of internationalization of higher education in East Asia (such as China), and typical developed countries (such as USA) can be fitted into the understanding of this broad framework of development strategies of the countries. Given the current shift or extension of developmental states from export-oriented and investment-led growth to knowledge-intensive or knowledge-based economy, the country in China is facing the internationalization brain race, which affects the governmental policies in higher education (Jessop, 2016). Therefore, China and the United States are selected as the research object.

To compare the internationalization of higher education of these 2 countries (China \& USA) from the policy perspective, the classical way was mainly based on two theories, including the globalization theory and the path dependence theory. From the globalization theory perspective, globalization sees the local or regional development of economy, politics, and culture in response to being impacted by globalization (Giulianotti \& Robertson 2006). However, it is noted that, the impact of globalization on one particular country may be different from another nation (Palmer \& Cho, 2012). The concepts of the globalization theory provide the theoretical groundings of understanding the policies of China and USA in forming the strategies for higher education internationalization, allowing for each country to develop its own policies in response to globalization's impact on their higher education (Tight, 2019). The path dependency theory, on the other hand, provides the theoretical pathway of analysing and comparing the impacts of different policies on developing higher education internationalization. Path dependence is defined as "a property of contingent, nonreversible dynamic processes, including a wide array of biological and social processes that can properly be described as evolutionary" (David, 2001). It offers a way of explaining the decisions/policies in any given context are influenced by the past decisions/policies (Hammond, 2016).

When measuring the internationalization level of a country's internationalization of higher education, there are many indicators to choose, such as the number of foreign students absorbed, the number of foreign students sent, and the number of international exchange projects. As shown in Figure 1, comparing the number of historical foreign students in China and the United States, it can be seen that the number of Chinese foreign students is gradually increasing after the United States. In fact, due to the universities in developing countries tending to develop in the direction of assimilating western higher education standards (Jung, 2018; Palmer \&amp; CHO, 2012; pinna, 2009). And the 
basic structure of China's higher education system comes from the West, In particular, standards and rules from the United States and the European Union. The process of internationalization of higher education in China must be like that in the United States. In addition to China, Japan and South Korea also build modern western higher education through learning the developed (Kim, 2009).

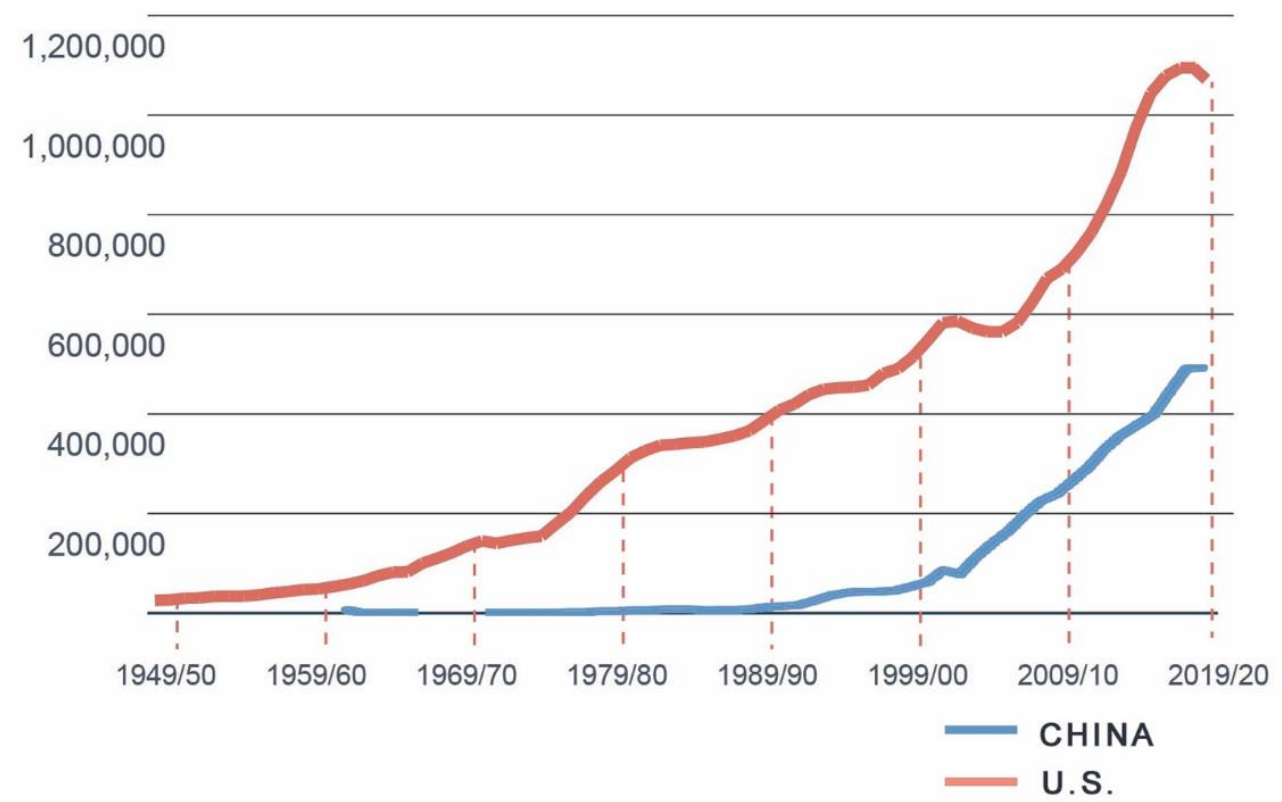

Figure 1. International Students in The United States and China 1949/50-2019/20

Therefore, the study aims to offer comparative analyses of the internationalization and development phenomena of higher education in China and USA in the context of the political development of the two countries, both of which are well-known for their economic success in the $20^{\text {th }}$ and contemporary century. The study framework of policies on higher education is from the late 1990s till now, considering China started implementing the opening-up policy in the 1990s. Although both countries have experienced astonishing economic development through economy and investment-led growth, the two countries have their distinct characteristics regarding cultural and political development strategies. Notably, the study tends to have a special focus on understanding the internationalization of higher education of China and USA in the context of their political strategies. To achieve the research purpose, the proposed research attempts to answer the below questions:

(1) How does a policy affect the internationalization of higher education?

(2) What are the contents of internationalization of higher education in the context of their political strategies?

\section{Research Method and Data}

The proposed study will adopt a mixed of qualitative and quantitative research methods:

-Systematic document review

The first stage of the study will be starting with collecting a large number of policy-related documents, including government reports, policies, regulations, projects, plans and so forth, which are related to the internationalization of higher education during the period of 1990 to 2020, in both China and USA. Considering the large amount of policy documents within this time period, the study will focus on policy texts and not empirically interrogating policy implementation or enactment (Palmer \& Cho, 2012). This will provide a rich dataset for a systematic review of polices on the internationalization of higher education during this time period. In addition, rather than treating the 
policies as a whole, the study will categorize them into different groups and levels that are directly related to the internationalization of higher education. It is not possible to analyse ever one of the policy documents, considering there are numerous policy documents related to the internationalization of higher education. Thus, the study will set a selection rule to make the research manageable, mainly based on the policy pool pertaining to internationalization of higher education for both countries. The pool of polices can then be further categorized to policies targeting on: nationfocused policy (overarching meta-policy), institution-focused policy, and individual people-focused policy (Palmer \& Cho, 2012).

-Case study

The study will explore polices that were designed both directly and not directly help the development of higher education internationalization. Selection of these policies will be based on the review of relevant studies. The study will give review in the content of economical and political strategies. Data used for case study will be sourced from the specific policy documents and relevant databased for the policy (e.g., BRI database: https://www.refinitiv.com/en/belt-road-initiative-datainsight, U.S. OpenDoors report: https: //opendoorsdata.org).

\section{Analysis}

\subsection{Investment Factors in Higher Education Internationalization Policy}

Education internationalization policy belongs to education policy, which is inseparable from government support. In the political and economic context, one of the indispensable means of policy support is capital investment.

As a pioneer in the internationalization of higher education, the United States started early and invested heavily in the internationalization of higher education. In 1946, Truman signed the Fulbright act 1946, marking the official intervention of the federal government in international education. The main content is to use the foreign exchange obtained from the sale of war surplus materials as a fund for educational exchanges to fund American citizens to go abroad and foreign citizens to study, research, and teach in the United States. After the economic sources relied on by the Fulbright act were gradually exhausted, fortunately, the U.S. economy developed rapidly after World War II. The economic sources of the Fulbright act and a series of subsequent supplementary agreements and a series of funded projects were transformed into fully-funded government grants. Through a large amount of capital investment, the number of foreign students in the United States has maintained a high growth from 1950 to 2020 . It can be said that the memorandum on international education policy signed by Clinton in the early 2000 century summarizes and arranges relevant policies for this development stage. This document further emphasizes the importance of international education and its relationship with the national status of the United States and simplifies the relevant procedures required for the international investment of American Higher Education.

However, once the capital investment is reduced, growth will immediately stagnate. The first federal government budget released by trump in 2017, the first in the United States: make American great again, reducing education funds by $13 \%$. As a result, a series of projects including Fulbright's subsidiary projects and other projects requiring financial support immediately had a significant negative impact. Due to the loss of financial support, the growth of the number of students studying in the United States began to slow down, and the number of foreign students in the 2019-2020 academic year showed the first negative growth since 2005 (the reason for the negative growth in 2002-2005 was the 9 / 11 incident).

Similarly, a series of policies issued by the Chinese government to develop the internationalization of higher education also include many direct/indirect capital investment methods, among which scholarship and tuition fee reduction policies are closely related to the growth of the number of foreign students. Since 1973, various regions of China have issued relevant regulations to help colleges and universities apply for subsidies for recruiting international students from local governments or national finance. Various trial regulations from 1970 to 2000 were finally summarized and finalized 
Volume 3 (2021)

in the regulations on the administration of enrolment of colleges and universities issued in 2000 . These policies have helped China shift the source of students from a single socialist neighbouring country to more than 180 countries in Europe, Africa, and Asia (1973-2017). At the same time, the scope and level of disciplines for foreign students have also been continuously improved. When China resumed accepting foreign students in 1973, more than 300 students were enrolled in a single Chinese language discipline. In 2017, a total of 58600 Chinese government scholarship students entered the fields of Western medicine, engineering, economics, and management, including 51600 academic students, accounting for $88.02 \%$ of the total number of scholarship students, and 40800 master and doctoral postgraduates, accounting for $69.57 \%$ of the total number of scholarship students.

By analysing the economic factors in the internationalization policies of higher education in China and the United States, it can be found that the most direct and effective way for the government to support the internationalization of higher education is capital investment, and the direct impact is the growth of the number of foreign students.

In addition, comparing figures 1 and 2, it can be seen that the number of foreign students absorbed by China began to grow rapidly when China's GDP increased significantly around 1990. It can be seen that the investment of funds involved in education policy is closely related to national economic growth.

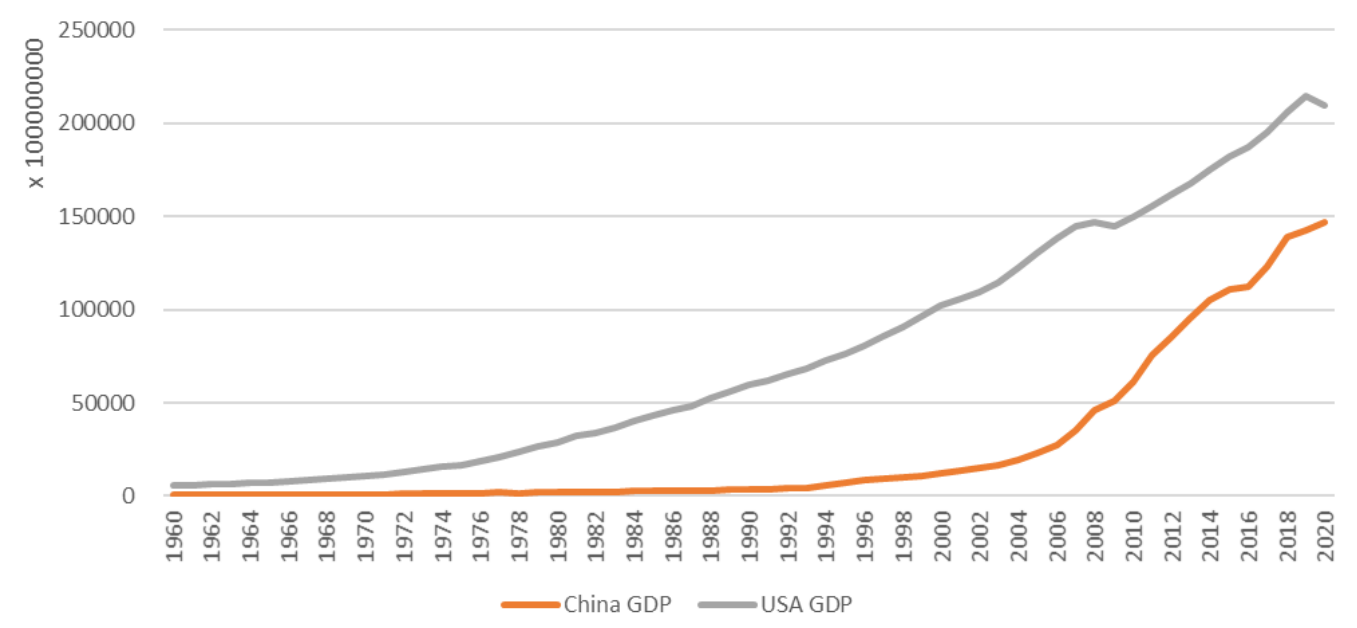

Figure 2. GDP of The United States and China 1960-2020 (in U.S. Dollar)

\subsection{Political Considerations in Higher Education Internationalization Policies}

If a large amount of financial support can rapidly increase the absolute number of foreign students, what a good international education country needs to do is to improve the quality of education internationalization. The efforts of the United States in this regard are to use its own influence to increase the exchange of foreign students and personnel, strengthen cultural communication, train the next generation of regional experts, and then enhance its international influence. China's efforts in this regard are like those of the United States. In addition to providing sufficient support for exchange projects, China also enhances regional leadership by actively exporting culture.

In 1992, the United States passed the act on expanding cultural and educational exchanges, which made positive instructions for the internationalization of higher education in the United States. At the same time, it applied for the additional US $\$ 40$ million, most of which was used to expand exchanges with the former Soviet Union. The act marked the end of the struggle of international consciousness and promoted the cooperation between colleges and universities on attracting teachers from different camps in the world for researches and projects.

Such exchanges were suspended after the $9 / 11$ incident. For the sake of national security, the United States successively promulgated the American Patriot Act and the 2002-2007 strategic plan of the U.S. Department of education, limiting the academic activities and research fields of foreign students and scholars. Subsequently, in 2005, to re-boost talent and project exchanges, the U.S. 
Congress established the "Abraham Lincoln Overseas Study Award Committee" and passed the committee's "global capabilities and national needs: one million Americans studying abroad" plan. Instead, it strengthened international exchanges by increasing American students studying abroad to enhance the influence of the United States in various regions around the world. The plan was officially launched in 10 years, covering not only Britain and EU countries, but also Eastern European countries and African countries.

Like the United States, after foreign students in China reached a certain level and scale, China also began to seek quality development. In 2003, China's State Council issued the regulations on Sino foreign cooperation in running schools, which formed Sino foreign cooperation in running schools by introducing foreign high-quality educational resources, and finally formed a long-term and stable personnel exchange and mutual visit system by driving personnel through projects. After that, a series of Chinese and foreign joint universities such as Nottingham University in Ningbo, Liverpool University in the western suburbs, and New York University in Shanghai were established one after another. The stable operation of Sino foreign cooperative school running projects not only brings a platform for talent exchange to China but also shows that China has made a step forward in opening to the outside world and the competition of international educational exchanges.

Like the program implemented by Abraham Lincoln's Overseas Study Award Committee, after 2003, the China national study abroad fund committee also established public funding programs, overseas youth talent programs, and other international exchange funding programs, covering multilevel talent exchange support from publicly sent overseas students to jointly run doctoral students. At the same time, to break the natural disadvantages of non-English speaking countries in international exchanges, China has put forward a series of Chinese popularization projects, such as "Chinese Bridge" and "Confucius Institute". China's one belt, one road regional cooperative development plan has made great contributions in the past 10 years and has greatly facilitated China's regional cooperation.

It can be seen that the national support for the export of education, culture, and ideology can be transformed into the part of talent exchange in the internationalization policy of higher education, and the development of the internationalization of higher education often provides positive feedback to the improvement of national, international and regional leadership.

\section{Conclusion}

Here, the answers to the two research questions raised above could be told. The internationalization policy of higher education covers the design of politics and the economy. It promotes the internationalization of higher education using capital investment and additional national influence. The common development strategy of a country's internationalization of higher education can be reflected in the following aspects: 1 . Attracting overseas students; 2 . Send local students; 3 . Exchange of teachers, researchers, and joint programs.

For a developed country, to continue to develop the internationalization of education in the face of the challenges of current international education opponents means that the country hopes to maintain its international status. The further development of education can not only maintain the leading level of education but also better consolidate its world political status. For a developing country, the internationalization of education also shows that the country is changing or expanding from export-oriented and investment-oriented growth. It needs to invest more in the international talent competition and scientific research development, and establish regional influence.

\section{Acknowledgments}

This work has been supported by Asia Education Institution (SG) since 2020, Project number: AEI201227G. 


\section{References}

[1] David, P. (2001). Path Dependence, Its Critics and the Quest for 'Historical Economics'. In Evolution and Path Dependence in Economic Ideas: Past and Present, 15, 40.

[2] Giulianotti, R., \& Robertson, R. (2006). Globalization, globalization and migration: The case of Scottish football supporters in North America. International Sociology, 21(2), 171-198.

[3] Hong, M. (2020). A comparative study of the internationalization of higher education policy in Australia and China (2008-2015). Studies in Higher Education, 45(4), 768-779.

[4] Hammond, C. D. (2016). Internationalization, nationalism, and global competitiveness: a comparison of approaches to higher education in China and Japan. Asia Pacific Education Review, 17(4), 555-566. https: //link.springer.com/article/10.1007/s12564-016-9459-0.

[5] Huang, F. (2006). Internationalization of curricula in higher education institutions in comparative perspectives: Case studies of China, Japan and the Netherlands. Higher Education, 51(4), 521-539.

[6] Jessop, B. (2016). Putting higher education in its place in (East Asian) political economy. Comparative education, 52(1), 8-25.

[7] Kim, T. (2009) "Confucianism, Modernism and Knowledge: China, South Korea and Japan (Chapter 55)." In International Handbook of Comparative Education, edited by R. Cowen, and A. Kazamias, 857-872. Dordrecht: Springer.

[8] Lee, J., Liu, K., \& Wu, Y. (2020). Does the Asian catch-up model of world-class universities work? Revisiting the zero-sum game of global university rankings and government policies. Educational Research for Policy and Practice, 1-25.

[9] Lianming, Li. The adjustment of American higher education internationalization policy and its impact after the 9/11 [J]. Global education outlook, 2009, (10).

[10] Palmer, J. D., \& Cho, Y. H. (2012). South Korean higher education internationalization policies: Perceptions and experiences. Asia Pacific Education Review, 13(3), 387-401.

[11] Peters, M. A. (2020). China's belt and road initiative: Reshaping global higher education. Educational Philosophy and Theory, 52 (6), 586-592.

[12] Sanders, I. T. \& Ward, J. G. Bridges to Understanding: International Programs of American College and Universities[M]. New York: Megraw-Hill Book Company,1970.135.

[13] Tight, M. (2019). Globalization and internationalization as frameworks for higher education research. Research Papers in Education, 1-23.

[14] The Institute of International Education. The Open Doors 2019 Report on International Educational Exchange [R]. New York: The Institute of International Education, 2019.

[15] Thompson, M. R. (1996). Late industrialisers, late democratisers: developmental states in the Asia-Pacific. Third World Quarterly, 17(4), 625-648.

[16] UNESCO (1998) World Conference on Higher Education. "Higher Education in the 21st century, Vision and Action", Vol. I Final Report. UNESCO, Paris, 5-9 October 1998. Retrieved 19 August 2020 from: http:// unesdoc.unesco.org/images/0011/001163/116345e.pdf.

[17] Vogel, E. F. (2013). Japan as number one: Lessons for America. Harvard University Press.

[18] Wihlborg, M., \& Robson, S. (2018). Internationalization of higher education: Drivers, rationales, priorities, values and impacts. European journal of higher education, 8(1), 8-18.

[19] Zengfu Yu, Jiang Bo, Xiaoyu Zhu. History of international exchanges and cooperation in Education [M]. Haikou: Hainan Publishing House, 2001:79,40,20-22118-120,19,75-77. 